\title{
Novel point mutation in the sodium channel gene of pyrethroid-resistant sea lice Lepeophtheirus salmonis (Crustacea: Copepoda)
}

\author{
Anders Fallang ${ }^{1, *}$, Ian Denholm ${ }^{2}$, Tor Einar Horsberg ${ }^{1}$, Martin S. Williamson ${ }^{2}$ \\ ${ }^{1}$ Norwegian School of Veterinary Science, PO Box 8146 Dep, 0033 Oslo, Norway \\ ${ }^{2}$ Rothamsted Research, Harpenden, Herts AL5 2JQ, UK
}

\begin{abstract}
Knockdown resistance (kdr) to pyrethroid insecticides is caused by point mutations in the pyrethroid target site, the para-type sodium channel of nerve membranes. This most commonly involves alterations within the domain II (S4-S6) region of the channel protein, where several different mutation sites have been identified across a range of insect species. To investigate the possibility that a kdr-type mechanism is responsible for pyrethroid resistance in sea lice, a domain II region of the Lepeophtheirus salmonis sodium channel gene was PCR amplified and sequenced. To our knowledge, this is the first published sodium channel sequence from a crustacean. Comparison of sequences from a range of samples, including several individuals from areas in which control failures had been reported, failed to identify any of the mutations within this region that have previously been linked with resistance. Instead, a novel glutamine to arginine mutation, Q945R, in transmembrane segment IIS5 was consistently found in the samples from areas of control failure and may therefore be associated with resistance to pyrethroids in this species.
\end{abstract}

KEY WORDS: Sea lice $\cdot$ Lepeophtheirus salmonis $\cdot$ Insecticide resistance $\cdot \mathrm{kdr} \cdot$ Pyrethroid

\section{INTRODUCTION}

Sea lice Lepeophtheirus salmonis (Krøyer) are ectoparasitic copepods that feed on several salmonid species. These parasites are a major cause of economic loss in the aquaculture industries of Northern Europe, the USA, Canada, and the Pacific coast of Japan (Denholm et al. 2002, Grant 2002). Since the mid 1990s, the synthetic pyrethroid insecticides cypermethrin ('Excis' and 'Betamax', Novartis) (Hart et al. 1997) and deltamethrin ('AlphaMax', Alpharma) have almost completely replaced organophosphates for lice treatments and were used in more than $90 \%$ of the treatments in Norway for sea lice in 1999 (Denholm et al. 2002). Several clinical treatment failures with deltamethrin and cypermethrin have been reported from Norway (Sevatdal \& Horsberg 2000), and reduced sensitivity has been documented using bioassays (Sevatdal \& Horsberg 2003).

Pyrethroid insecticides have been used widely to control many arthropod pests since their introduction in the 1970s. However, because of their intensive use, many pest species have developed resistance to these compounds. This has stimulated extensive research into the incidence of resistance and the nature of the underlying mechanisms. Knowledge of resistance mechanisms is a valuable tool for developing strategies to detect and manage the spread of resistant individuals (Horowitz \& Denholm 2001).

The primary target site for pyrethroids is the voltagegated sodium channel, a large membrane protein that mediates the increase in sodium ion permeability during the rising phase of action potentials in neurons and other excitable tissues (Catterall 2000). Pyrethroids modify the normal operation of the channel by slowing its activation and inactivation kinetics, which results in uncontrolled bursts of action potentials leading to nerve exhaustion and death (Narahashi 1992). Pyrethroids are excellent insecticides because they selectively target the sodium channels of arthropods with little cross-toxicity to mammals. In insects, the 
main voltage-gated sodium channel is encoded by the para gene that was first cloned from Drosophila melanogaster (Loughney et al. 1989). Subsequent studies have generated full or partial sequences of para gene homologues from a range of insect species (reviewed in Soderlund \& Knipple 2003). The insect channel protein is similar to that in vertebrates, consisting of 4 internally repeating homology domains (I-IV) with a minimum of 6 membrane-spanning segments (S1-S6) in each domain (Catterall 2000).

An important mechanism of pyrethroid resistance, termed knockdown resistance (or kdr), is characterised by a reduced sensitivity of the insect nervous system to these compounds and is caused by alterations to the para-type sodium channel protein that render it less sensitive to the toxic effects of these insecticides. Mutations leading to resistance are most commonly located in the domain II region of the channel protein and have now been identified at 5 different residues (see Vais et al. 2001, Soderlund \& Knipple 2003 and references therein). The most common is leucine 1014, where mutations to phenylalanine (L1014F), serine (L1014S) and histidine (L1014H) generally confer moderate levels of resistance (10 to 30 fold) to pyrethroids. Other secondary mutations in this domain that give enhanced (super-kdr) resistance include methionine 918 to threonine (M918T) in housefly Musca domestica (L.) and horn fly Haematobia irritans (L.) (Williamson et al. 1996, Guerrero et al. 1997), threonine 929 to isoleucine (T929I) in diamondback moth Plutella xylostella (L.) and head louse Pediculus humanis (L.) (Schuler et al. 1998, Lee et al. 2000) and leucine 925 to isoleucine (L925I) in tobacco whitefly Bemisia tabaci (Genn.) (Morin et al. 2002). These secondary mutations are usually found in combination with the L1014F kdr mutation and give enhanced resistance levels of up to 1000 fold for certain pyrethroids. Mutations have also been reported outside domain II, although there is evidence that these may incur fitness penalties and none of these have yet been found in more than one species (Park et al. 1997, Pittendrigh et al. 1997, Head et al. 1998, He et al. 1999, Liu et al. 2000). All mutation numbering in this paper is based on the housefly para sequence (EMBL accession CAA65448) where $\mathrm{kdr}$ mutations were first identified.

Little is known about the mechanism(s) of pyrethroid resistance in sea lice. The current study was conducted to investigate whether one or more of the mutations described above also cause pyrethroid resistance in sea lice. We have PCR-amplified and sequenced regions in domain II of the Lepeophtheirus salmonis para-type sodium channel gene that contain 5 of the mutation sites conferring kdr-type resistance to pyrethroids in insects, including the common L1014F mutation site. The predicted amino acid sequences from pyrethroid sensitive and resistant $L$. salmonis individuals have been compared. We report a single amino acid substitution, glutamine 945 to arginine (Q945R) that was only found in pyrethroid resistant lice samples and may therefore represent a novel mutation site in the domain II region of the sodium channel.

\section{MATERIALS AND METHODS}

Experimental sea lice strains. Sea lice were collected from salmon farms in selected regions in Norway (Fig. 1). The selection was based partially on geography, but also on reports of treatment failure or reduced pyrethroid sensitivity documented by bioassays (Sevatdal \& Horsberg 2003). Atlantic salmon were netted from cages at the fish farm, and anaesthetized lightly with benzocaine $\left(50 \mathrm{mg} \mathrm{l}^{-1}\right)$. The parasites were gently removed using forceps, snap frozen in liquid nitrogen and subsequently stored at $-80^{\circ} \mathrm{C}$. In cases of treatment failures with pyrethroids, only individuals surviving the treatment were collected to maximise the chances of selecting resistant individuals.

Resistance history. There were no reports of resistance from farms in Brekke, Tysnes and Sveio and bioassays confirmed normal sensitivity. In Hitra, Bømlo and Hjelmeland the fish health service reported clinical treatment failures with pyrethroids, which were confirmed by bioassays (Sevatdal \& Horsberg 2003). From Dirdal, there were only anecdotal reports of treatment failures.

RT-PCR amplification and cloning of sea lice sodium channel fragments. Frozen adult sea lice were ground to

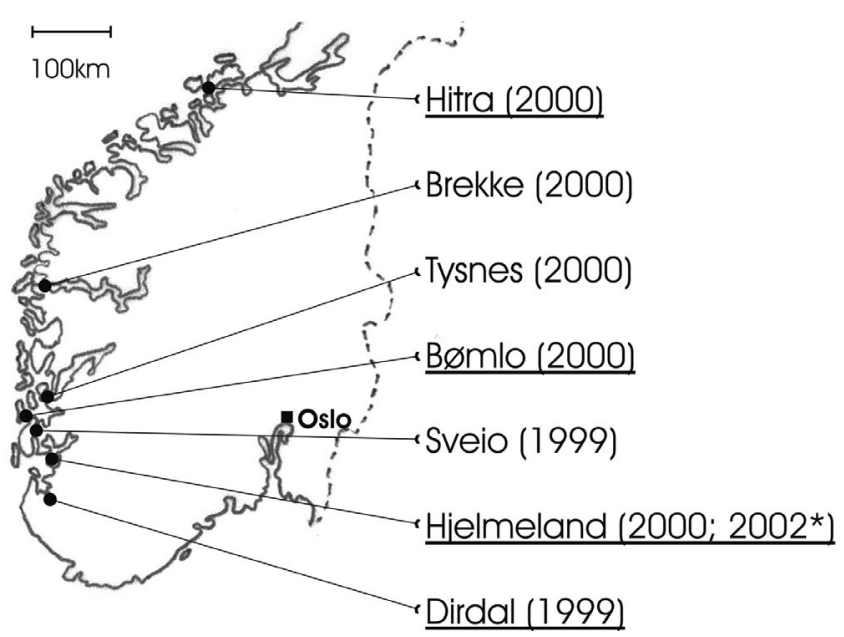

Fig. 1. Location of the sampling areas for Lepeoptheirus salmonis in Norway. Underlined sites are areas where the Q945R mutation was detected. *: The mutation was only detected in samples from 2002 in this area 
a fine powder in liquid nitrogen in $1.5 \mathrm{ml}$ microfuge tubes using tight-fitting pestles. Total RNA was then extracted using the SV Total RNA Isolation kit from Promega (Madison, WI). For first-strand synthesis, $5 \mu \mathrm{g}$ RNA was incubated with $0.5 \mu \mathrm{g}$ Oligo (dT) at $70^{\circ} \mathrm{C}$ for $10 \mathrm{~min}$ and placed on ice for $1 \mathrm{~min}$. Synthesis buffer (2.5 mM MgCl $2,0.5 \mathrm{mM}$ dNTP and $10 \mathrm{mM}$ DTT) and 200 units Superscript II RT (Life Technologies) were added and the reactions incubated at $42^{\circ} \mathrm{C}$ for $50 \mathrm{~min}$. The reactions were terminated at $70^{\circ} \mathrm{C}$ for $15 \mathrm{~min}$ and these products used as templates for PCR. Degenerate oligonucleotide primers were designed for conserved motifs in previously published sodium channel sequences (Williamson et al. 1996, Martinez-Torres et al. 1997) available in the EMBL/GenBank databases. Primer sequences used in this study are shown in Table 1, and their location on the sodium channel are shown in Fig. 2A \& B. PCR amplifications using primers SCLS-1F and SCLS-2R for the primary reaction, followed by primers SCLS-3F and SCLS-2R for secondary, nested reactions produced a fragment of approximately $250 \mathrm{bp}$ which included the known domain II mutation sites. Separate reactions using primers SCLS-12F and SCLS$27 \mathrm{~F}$ for the primary reaction followed by primers SCLS$6 \mathrm{~F}$ and SCLS-27F for the secondary reaction were used to amplify a fragment of approximately $1.9 \mathrm{~kb}$ that spanned segments IIS4 through to domain IIIS3. All PCR amplifications were done in $50 \mu \mathrm{l}$ reaction volumes with $100 \mathrm{ng}$ genomic DNA, $1 \times$ buffer containing $1.5 \mathrm{mM}$ $\mathrm{MgCl}_{2}, 200 \mu \mathrm{M}$ dNTPs, $1 \mu \mathrm{M}$ of each primer and 1 Unit Taq polymerase (Qiagen). The reactions were hotstarted by denaturation at $94^{\circ} \mathrm{C}$ for $4 \mathrm{~min}$ and run through 35 cycles of $30 \mathrm{~s}$ at $94^{\circ} \mathrm{C}, 1 \mathrm{~min}$ at $50^{\circ} \mathrm{C}$ and $1 \mathrm{~min}$ at $72^{\circ} \mathrm{C}$ with a final elongation for $10 \mathrm{~min}$ at $72^{\circ} \mathrm{C}$. The products were cloned into the pMOSBlue vector (Amersham Pharmacia Biotech) and sequenced using Big Dye

Table 1. Primer sequences used in the study. Degenerate bases are represented using standard IUB codes: $\mathrm{R}=\mathrm{A}+\mathrm{G}, \mathrm{Y}=\mathrm{C}+\mathrm{T}, \mathrm{M}=\mathrm{A}+\mathrm{C}$, $\mathrm{N}=\mathrm{A}+\mathrm{C}+\mathrm{G}+\mathrm{T}$. The degeneracy of each primer is shown

\begin{tabular}{|llc|}
\hline Primers & Sequence & Degeneracy \\
\hline Degenerate & & \\
SCLS-1F & 5'- AARYTNGCNAARTCNTGGCC -3' & 128 \\
SCLS-2R & 5'- ARRAANARRTTNARNACCAC -3' & 2048 \\
SCLS-3F & 5'- GCNAARTCNTGGCCNAC -3' $^{\prime}$ & 128 \\
SCLS-27F & 5'- ACITTYMGIGTNYTIMGNGC -3' & 256 \\
For genomic DNA & \\
SCLS-6F & 5'- CCACACTGAACTTGCTCATATC -3' & \\
SCLS-7R & 5'- AGTCCACAAAGTTCCAACGG -3' & \\
SCLS-8R & 5'- GGATTTGTTAGGGAATCGGTC -3' & \\
SCLS-12F & 5'- CATGGCCCACACTGAACTTG -3' & \\
SCLS-14F & 5'- CCTTTGTGGTGAATGGATCG -3' & \\
SCLS-15F & 5'- TCCATGTGGGACTGTATGTG -3' & \\
SCLS-25R & 5'- TGCAGCCGAGAGATTTGAAT -3' & \\
& & \\
\hline
\end{tabular}

terminator v1.1 cycle sequencing kit (Applied Biosystems) on Applied Biosystems 377 or 310 sequencers. Sea lice-specific para gene primers (Table 1) were designed from the sequences obtained and these improved the efficiency of the PCR reactions. These primers also allowed the use of genomic DNA as template for amplification in subsequent reactions.

Amplification from genomic DNA. Genomic DNA was extracted using DNeasy Tissue kit from Qiagen. Between 4 and 10 lice were analysed from each sampling area. Gene fragments spanning the major mutation sites (L1014, T929, M918, etc.) were amplified in 2 separate PCR amplifications. Primers SCLS-6F and SCLS-7R amplified a product of $1388 \mathrm{bp}$ that included an intron of $1202 \mathrm{bp}$. Primers SCLS-14F and SCLS-25R amplified a product of $166 \mathrm{bp}$ (Fig. 2A, Table 1). PCR conditions were as described above, except that $50 \mathrm{ng}$ genomic DNA was used as template. PCR gene fragments were directly sequenced as described above using the internal primers, SCLS-15F and SCLS-16R, designed from the cDNA sequence (Table 1). All sequences were analysed using the Vector NTI software package (Informax).

The Lepeophtheirus salmonis para sodium channel sequence was deposited in EMBL nucleotide sequence database with accession number AJ812299.

\section{RESULTS}

Using degenerate primers for the domain II region of the known sodium channel sequences, we amplified and sequenced a $318 \mathrm{bp}$ fragment of the Lepeophtheirus salmonis para-type sodium channel gene. This region contains 5 of the mutation sites previously associated with kdr-type resistance in a range of insect species including the common L1014F mutation site. The nucleotide and encoded amino acid sequences of this fragment, including the nucleotide sequence of an accompanying intron, are shown in Fig. 3. This is the first sodium channel sequence reported for a crustacean. An alignment of a 106 amino acid conserved sequence, encompassing the M918 and L1014 mutation sites, against a range of other vertebrate and invertebrate sequences is shown in Fig. 4. The L. salmonis sequence showed $75 \%$ similarity to the bee pathogen Varroa destructor Anderson (AY259834) and $73 \%$ similarity with the cattle tick Boophilus microplus Canestrini (AF134216) within this region of the para-type sodium channel (Fig. 5). Fig. 5 shows a phylogenetic tree, generated in Vector NTI ${ }^{\mathrm{TM}}$, depicting similarity between different sodium channel sequences. 


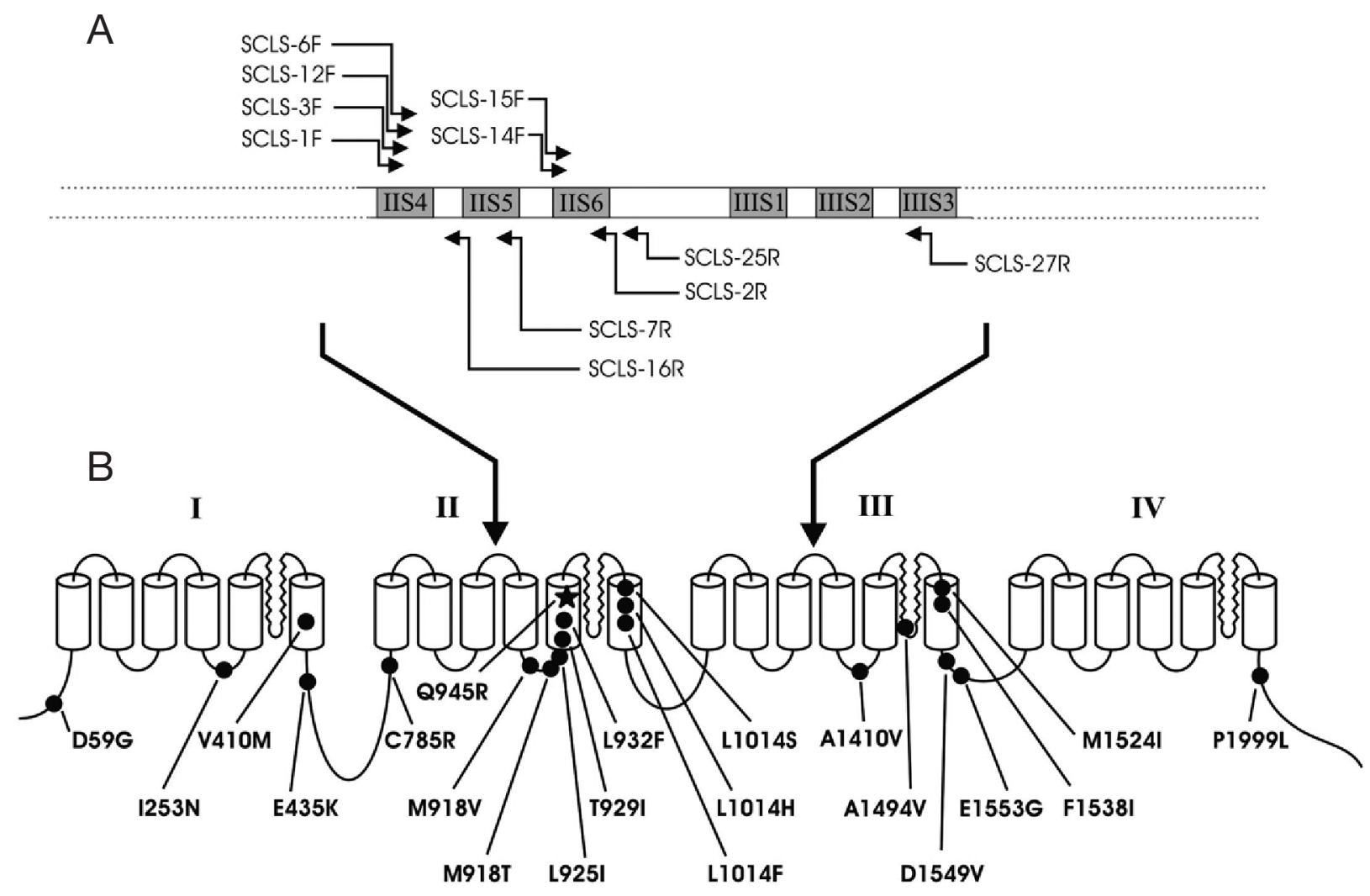

Fig. 2. (A) Positions of the oligonucleotide primers used to PCR amplify domain II sequences of the para sodium channel of Lepeophtheirus salmonis. (B) Proposed folding topology of the sodium channel protein within the membrane. ๑: locations of mutations that have been implicated in conferring resistance to pyrethroids. $\star$ : position of the L. salmonis Q945R mutation

The phylogenetic tree calculation is based on a sequence distance method and utilizes the Neighbor Joining (NJ) algorithm. The accession numbers of the different sequences are: Aphis gossyypii (AAL04160), Myzus persicae (CAA10504), Boophilus microplus (AF134216), Varroa destructor (AY259834), Lepeophtheirus salmonis (AJ812299), Drosophila melanogaster (AAF48167), Haematobia irritans (AAC12794), Musca domestica (CAA65448), Blattella germanica (AAC47483), Frankliniella occidentalis (CAC79234), Bemisia tabaci (CAD29437), Meligethes aeneus (AA049190), Heliothis virescens (AAC26513), and Plutella xylostella (CAA11217).

To look for possible mutations in pyrethroid resistant samples, it was necessary to switch from RT-PCR (using RNA as the template) to PCR using genomic DNA templates. This assay was more robust and enabled testing of individual lice samples. We therefore re-amplified these fragments from genomic DNA of single adults using lice-specific para primers designed from the cDNA sequence. This analysis allowed us to accurately determine the genotype of multiple individuals from various locations and also revealed the presence of a large intron (1202 bp) in this region of the gene (Fig. 3).

PCR products from a total of 47 adults from the 7 locations were sequenced (Table 2). None of the 5 previously identified mutations in this region of channel protein were detected, but a novel change from glutamine to arginine at the end of IIS5 at residue corresponding to Q945 of the housefly para sequence was found. The mutation was detected in samples from Hitra, Bømlo, Hjelmeland 2000 and Dirdal. The mutation was only detected in samples from areas with reported treatment failure with pyrethroids. The pyrethroid sensitivity was confirmed with bioassays in all samples except from Dirdal (Sevatdal \& Horsberg 2003).

\section{DISCUSSION}

New insecticide/pesticide/anti-parasitic compounds are expensive to develop, and as a consequence the management of organisms such as sea lice depends on maintaining the efficacy of the few chemicals avail- 


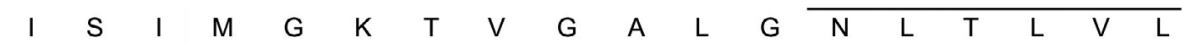
ATA TCC ATT ATG GGA AAA ACT GTG GGT GCA CTT GGA AAC TTG ACT CTG GTT TTA IIS5

\begin{tabular}{cccccccccccc|c|ccccc}
\hline C & I & I & I & F & I & F & A & V & M & G & M & Q & L & $F$ & G & $K$ & $S$ \\
TGT & ATC & ATT & ATC & TाT & ATA & TTC & GCA & GTA & ATG & GGA & ATG & CAA & CTA & TIT & GGG AAG AGC
\end{tabular}

Y $V$

TAC GTG ggtaagaaaggactaagaatccacatattgccaattacttttatatgtcaaacaggatgtttgtccaaaagtacaaaatacat caaaaataaatgaaggcatcacattttaaaatgaacacaaattgaatatgtatttaaccctcctttatcacacagggatattatatacccegag atttattaaaatatttattattcctttaaatctaaaaacaaaacttctgaacaaaaatctgataattttaattcattatttatcttgttaatgaattgctta agattttttgaagatttgcaattttaatcgaagtttagtaaattaaaaaagtgcttaattggtgaataatacaaataaatcattcattttattaaatg gtcatgtcaaaccgactaaaaataatgagatatgaattataagtatattgtttaatattaataaaatgtgtgcgtaagggtagatttatgtacatttat aatatgtacaatataatactcgagaatatgacatcattatattaatggagtccgtcttgtccgtcctccttcaagcctaatcctatttattcgtgtcct ctattccgttgcaataataatataatctagatccttaacacacgagtatgtatacagacactttccctaatttaatttagatttgtattaaatattgata attatcagtgtgtgccatctacgagtatttatgtacattatacggactatcatattagatgccattgaagaggaagagacaaaattcaaatagctt catttctagagccataatacttaattaaaataattttaaagtcataaaaaaatgagatatacatatttttaagtggggtccttgaaataaatatatcta aggatatgaaaaacgggcatttattgccttattttattactacatactacatggttgaaataactcgacttttattgacatattgagccttaactggtc $\begin{array}{ccccccccccc}\text { attaactactctgtagttaacttatcaaatctttcatttatttca } & \text { GAC } & \text { AAC } & \text { ATT } & \text { GAC } & \text { CGA } & \text { TTC } & \text { CCT } & \text { AAC } & \text { AAA TCC }\end{array}$

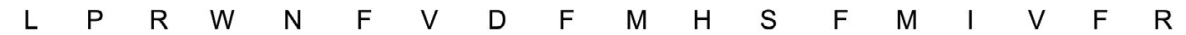
CTT CCC CGT TGG AAC TIT GTG GAC TIT ATG CAC AGC TTC ATG ATT GTG TIT AGA \begin{tabular}{cccccccccccccccccc}
$V$ & $L$ & $C$ & $G$ & $E$ & $W$ & I & $E$ & $S$ & $M$ & $W$ & $D$ & $C$ & $M$ & $W$ & I & A & $S$ \\
GTC & $C T T$ & TGT & GGT & GAA & TGG & ATC & GAG & TCC & ATG & TGG & GAC & TGT ATG TGG ATA & GCC TCA \\
\hline
\end{tabular} $\begin{array}{llllllllllllllllll}K & V & C & V & P & F & F & L & A & T & V & V & \text { I } & G & N & L & V & V\end{array}$ AAA GTC TGC GTT CCT TTC TTC CTA GCG ACG GTT GTG ATT GGG AAT CTC GTG GTT

\begin{tabular}{lccc}
\hline L & N & L & F \\
CTG & AAT & CTT & TIT
\end{tabular}

Fig. 3. Nucleotide and amino acid sequences of the Lepeophtheirus salmonis para-type sodium channel fragments (IIS5, IIS6) cloned in this study. Coding nucleotides are in uppercase and the intron sequence is in lower case. Transmembrane protein domains are shown by lines above the sequence. The Q945R mutation site is indicated with a box

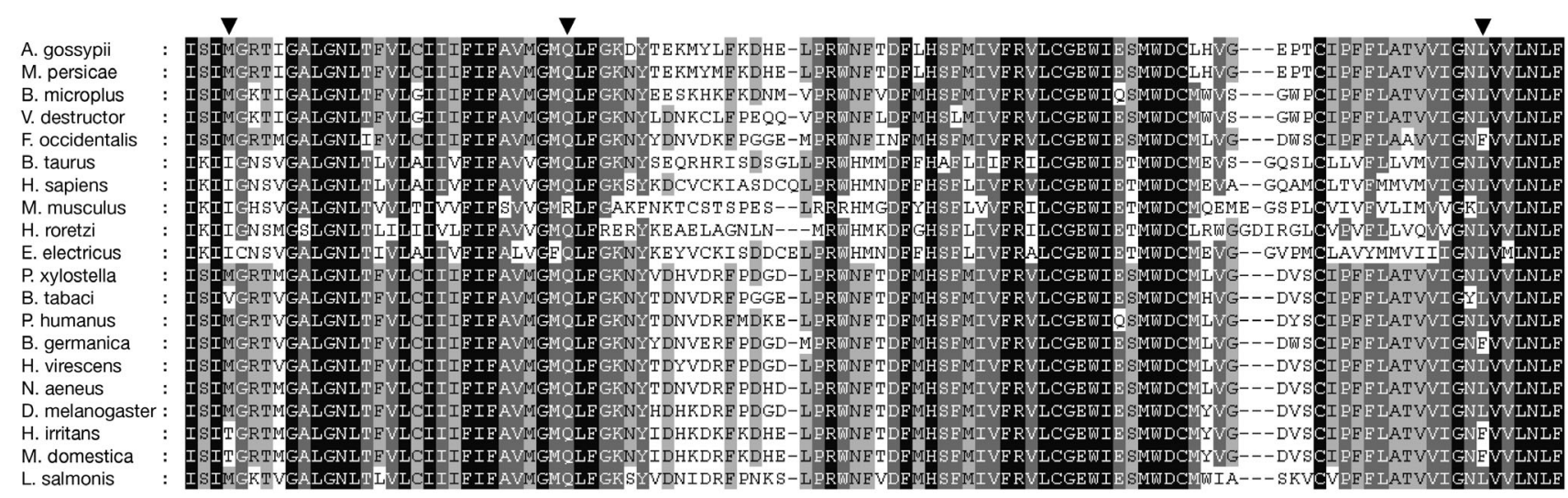

Fig. 4. Alignment of the Lepeophtheirus salmonis sodium channel sequences with corresponding sequences from a range of other organisms. $\mathbf{\nabla}$ : positions of the Q945R, M918T (super-kdr) and L1014F (kdr) mutation sites 


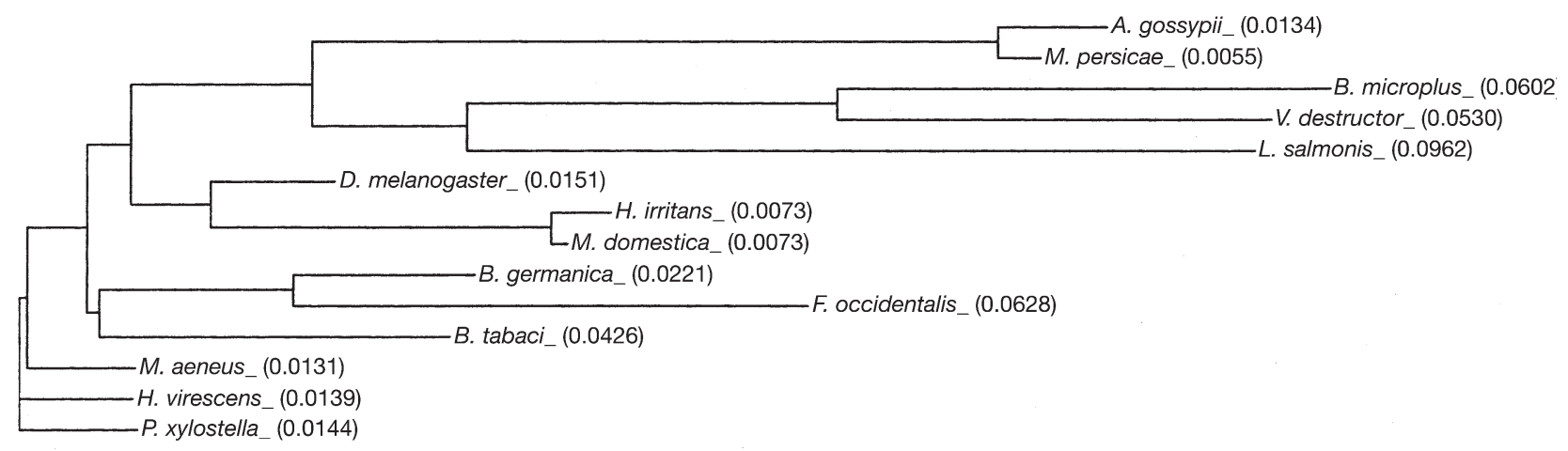

Fig. 5. Phylogenetic unrooted dendrogram depicting similarity between different sodium channel sequences. Branch lengths are proportional to the amount of inferred evolutionary change. Support values in parenthesis

able. The cloning and sequencing of sea lice sodium channel gene sequences described in this paper and the identification of a novel mutation potentially responsible for target site resistance to pyrethroids offers the opportunity of developing a molecular diagnostic tool that could quickly detect the mutation in individual sea lice and thereby facilitate the early detection of resistance in different populations.

Mutations in the sodium channel conferring $\mathrm{kdr}$ resistance to pyrethroids have been characterised in many pest species. There are potentially many resistance-associated mutation sites in the 4 homologous domains of the sodium channel (Soderlund \& Knipple 2003). However, most of the mutations found so far occur in the S4-S5, S5 and S6 segments of the domain II region of the channel protein. To date, 5 mutation sites that correlate with resistance in a range of insect species have been identified within this region. We therefore focused our work to look for similar mutation(s) in this region of the sea lice channel protein. Comparisons of the sequences of sensitive sea lice with lice from areas with documented reduced sensitivity to pyrethroids failed to reveal mutations at any of these

Table 2. Detection rate of mutation Q945R and reduced pyrethroid sensitivity for each sampling site. Nt: not tested

\begin{tabular}{|lcccc|}
\hline $\begin{array}{l}\text { Sampling } \\
\text { location }\end{array}$ & Year & $\begin{array}{c}\text { No. of samples } \\
\text { with mutation/ } \\
\text { Total sample size }\end{array}$ & $\begin{array}{c}\text { Reported clinical } \\
\text { treatment failure } \\
\text { with pyrethroids }\end{array}$ & $\begin{array}{c}\text { Sensitivity } \\
\text { confirmed } \\
\text { with } \\
\text { bioassays }\end{array}$ \\
\hline Hitra & 2000 & $3 / 6$ & Yes & Yes \\
Brekke & 2000 & $0 / 6$ & No & Yes \\
Tysnes & 2000 & $0 / 4$ & No & Yes \\
Bømlo & 2000 & $3 / 5$ & Yes & Yes \\
Sveio & 1999 & $0 / 4$ & No & Yes \\
Hjelmeland & 2000 & $1 / 10$ & Yes & Yes \\
Hjelmeland & 2002 & $0 / 10$ & No & Yes \\
Dirdal & 1999 & $4 / 6$ & Yes & Nt \\
\hline
\end{tabular}

known sites. We did, however, identify a single point mutation at a novel position in the IIS5 segment of the Lepeophtheirus salmonis channel. This mutation, Q945R (numbering according to the Musca domestica para sequence [CAA65448]), was located within a highly conserved region of the channel and involved a non-conservative replacement of an uncharged glutamine side-chain by a positively charged arginine residue. The occurrence of the mutation correlated with resistance, as it was only found in samples from areas with reports of treatment failures. These samples had also been confirmed through bioassays to show significantly reduced sensitivity to pyrethroids (Table 2) (Sevatdal \& Horsberg 2003).

In samples collected in 1999 from Sveio and Dirdal, the Q945R mutation was found only in Dirdal. These 2 areas are in different fjord systems and approximately $130 \mathrm{~km}$ apart. Analysis of samples from 2000 revealed the Q945R mutation in samples from Bømlo, Hjelmeland and Hitra. Samples from Bømlo had a high frequency of the mutation. This area is located approximately $20 \mathrm{~km}$ from Sveio and Tysnes. In spite of this, no mutations were detected in the Sveio and Tysnes samples. In Hitra, which is about $450 \mathrm{~km}$ north of Bømlo, the mutation was detected. However, in Brekke, which is between Bømlo and Hitra (about $180 \mathrm{~km}$ north of Bømlo), the mutation was not detected. The samples collected from Hjelmeland in 2002 showed normal sensitivity towards pyrethroids and the Q945R mutation, which was evident in the 2000 samples from this region, was not found. The areas in which the mutation has been detected thereby conform well with sensitivity data from bioassays and anecdotal reports of reduced efficacy of pyrethroids in delousing procedures.

Alignments of known vertebrate and invertebrate sodium channel sequences show a high degree of sequence conservation across 
this region of the channel protein, suggesting that this sequence is important for the normal function of the channel. It is therefore unlikely to tolerate polymorphisms, unless they exert an alternative selective advantage (e.g. conferring protection against insecticides). Indeed, all of the available sodium channel sequences in the EMBL/GenBank databases contain the glutamine residue at this position except for one of the mammalian channel isoforms (Scn11a, also known as Nav1.9) from mouse, Mus musculus and rat, Rattus norvegicus (AF118044 and AF059030), which also contains an arginine residue. Interestingly, this channel isoform is thought to be insensitive to tetrodotoxin (TTX), a highly potent sodium-channel blocking agent, although to our knowledge this residue has not been implicated as forming part of the TTX binding site.

To date there are reports of more than 20 different resistance-associated mutations (Soderlund \& Knipple 2003) (Fig. 2B). This implies that there could be resistance-associated mutations elsewhere in the sodium channel of Lepeophtheirus salmonis. Cloning of the full sodium channel gene is necessary to investigate other possible mutation sites. However, the detection of this new mutation in L. salmonis and the correlation with bioassay results and anecdotal reports of pyrethroid resistance is an intriguing finding. Because of the difficulty in cultivating several generations of sea lice in the laboratory to select for a highly resistant population, physiological expression studies will be necessary to study the importance of this new mutation in terms of its in vivo effect on pyrethroid sensitivity and other functional properties on the sodium channel. At present, there is little structural information regarding the binding site for pyrethroids at the voltagegated sodium channel. The sodium channel is a large, complex transmembrane protein and the difficulties in purifying and crystallising such proteins are well known. Hence, the information derived from the various mutations that have been shown to affect channel sensitivity are providing the first real clues as to which regions of the channel and which residues are involved in channel-pyrethroid interactions (Vais et al. 2001, Soderlund \& Knipple 2003). Several recent studies have successfully confirmed the mechanism of other mutations (L1014F, T929I and M918T) by expressing the wild-type and mutated sodium channel genes in Xenopus oocytes and assaying their sensitivity to pyrethroids using electrophysiological techniques (Smith et al. 1997, Lee et al. 1999, Vais et al. 2000, 2001). These studies have shown that the resistance mutations are able to affect channel sensitivity to pyrethroids in 2 ways: (1) by altering the physiological properties of the channel to make it a poorer template for pyrethroid binding, and (2) by reducing overall affinity of the channel for pyrethroids so that pyrethroid-modified channels are able to recover more quickly. Studies are now in progress to explore the functionality of the Q945R by similar methods.

Acknowledgements. This work was partly funded by an EU research grant (QLK2-CT-2000-00809 SEARCH), and partially by a grant from the Norwegian Research Council (134198/120). Rothamsted Research receives grant aided support from the Biotechnology and Biological Sciences Research Council of the United Kingdom.

\section{LITERATURE CITED}

Catterall WA (2000) From ionic currents to molecular mechanisms: the structure and function of voltage-gated sodium channels. Neuron 26:13-25

Denholm I, Devine GJ, Horsberg TE, Sevatdal S, Fallang A, Nolan DV, Powell R (2002) Analysis and management of resistance to chemotherapeutants in salmon lice, Lepeophtheirus salmonis (Copepoda: Caligidae). Pest Manag Sci 58:528-536

Grant AN (2002) Medicines for sea lice. Pest Manag Sci 58: 521-527

Guerrero FD, Jamroz RC, Kammlah D, Kunz SE (1997) Toxicological and molecular characterization of pyrethroidresistant horn flies, Haematobia irritans: identification of $\mathrm{kdr}$ and super-kdr point mutations. Insect Biochem Mol Biol 27:745-755

Hart JL, Thacker JRM, Braidwood JC, Fraser NR, Matthews JE (1997) Novel cypermethrin formulation for the control of sea lice on salmon (Salmo salar). Vet Rec 140:179-181

He H, Chen AC, Davey RB, Ivie GW, Wagner GG, George JE (1999) Sequence analysis of the knockdown resistancehomologous region of the para-type sodium channel gene from pyrethroid-resistant Boophilus microplus (Acari: Ixodidae). J Med Entomol 36:539-543

Head DJ, McCaffery AR, Callaghan A (1998) Novel mutations in the para-homologous sodium channel gene associated with phenotypic expression of nerve insensitivity resistance to pyrethroids in Heliothine lepidoptera. Insect Mol Biol 7:191-196

Horowitz AR, Denholm I (2001) Impact of insecticide resistance mechanisms on management strategies. In: Ishaaya, I (ed) Biochemical sites of insecticide action and resistance. Springer-Verlag, Berlin, p 323-338

Lee SH, Smith TJ, Knipple DC, Soderlund DM (1999) Mutations in the house fly Vssc1 sodium channel gene associated with super-kdr resistance abolish the pyrethroid sensitivity of Vssc1/tipE sodium channel expressed in Xenopus oocytes. Insect Biochem Mol Biol 29:185-194

Lee $\mathrm{SH}$, Yoon KS, Williamson MS, Goodson JM, Takano-Lee M, Edman JD, Devonshire AL, Clark JM (2000) Molecular analysis of kdr-like resistance in permethrin-resistant strains of head lice, Pediculus capitis. Pestic Biochem Physiol 66:130-143

Liu Z, Valles SM, Dong K (2000) Novel point mutations in the German cockroach para sodium channel gene are associated with knockdown resistance (kdr) to pyrethroid insecticides. Insect Biochem Mol Biol 30:991-997

Loughney K, Kreber R, Ganetzky B (1989) Molecular analysis of the para locus, a sodium channel gene in Drosophila. Cell 58:1143-1154 
Martinez-Torres D, Devonshire AL, Williamson MS (1997) Molecular studies of knockdown resistance to pyrethroids: Cloning of domain II sodium channel gene sequences from insects. Pestic Sci 51:265-270

Morin S, Williamson MS, Goodson SJ, Brown JK, Tabashnik BE, Dennehy TJ (2002) Mutations in the Bemisia tabaci sodium channel gene associated with resistance to a pyrethroid plus organophosphate mixture. Insect Biochem Mol Biol 32:1781-1791

Narahashi T (1992) Overview of toxins and drugs as tools to study excitable membrane ion channels: II. Transmitteractivated channels. Methods Enzymol 207:643-658

Park Y, Taylor MF, Feyereisen R (1997) A valine421 to methionine mutation in IS6 of the hscp voltage-gated sodium channel associated with pyrethroid resistance in Heliothis virescens F. Biochem Biophys Res Commun 239:688-691

Pittendrigh B, Reenan R, ffrench-Constant RH, Ganetzky B (1997) Point mutations in the Drosophila sodium channel gene para associated with resistance to DDT and pyrethroid insecticides. Mol Gen Genet 256:602-610

Schuler TH, Martinez-Torres D, Thompson AJ, Denholm I, Devonshire AL, Duce IR, Williamson MS (1998) Toxicological, electrophysiological, and molecular characterisation of knockdown resistance to pyrethroid insecticides in the diamondback moth, Plutella xylostella (L.) Pestic Biochem Physiol 59:169-192

Sevatdal S, Horsberg TE (2000) Kartlegging av pyretroid-

Editorial responsibility: Carey Cunningham,

Aberdeen, UK resistens hos lakselus. Nor Fiskeoppdrett 12:34-35 (in Norwegian)

Sevatdal S, Horsberg TE (2003) Determination of reduced sensitivity in sea lice (Lepeophtheirus salmonis Krøyer) against the pyrethroid deltamethrin using bioassays and probit modelling. Aquaculture 218:21-31

Smith TJ, Lee SH, Ingles PJ, Knipple DC, Soderlund DM (1997) The L1014F point mutation in the house fly Vssc1 sodium channel confers knockdown resistance to pyrethroids. Insect Biochem Mol Biol 27:807-812

Soderlund DM, Knipple DC (2003) The molecular biology of knockdown resistance to pyrethroid insecticides. Insect Biochem Mol Biol 33:563-577

Vais H, Williamson MS, Goodson SJ, Devonshire AL, Warmke JW, Usherwood PNR, Cohen CJ (2000) Activation of Drosophila sodium channels promotes modification by deltamethrin: Reductions in affinity caused by knockdown resistance mutations. J Gen Physiol 115:305-318

Vais $\mathrm{H}$, Williamson MS, Devonshire AL, Usherwood PNR (2001) The molecular interactions of pyrethroid insecticides with insect and mammalian sodium channels. Pest Manag Sci 57:877-888

Williamson MS, Martinez-Torres D, Hick CA, Devonshire AL (1996) Identification of mutations in the housefly paratype sodium channel gene associated with knockdown resistance $(\mathrm{kdr})$ to pyrethroid insecticides. Mol Gen Genet 252:51-60

Submitted: September 13, 2004; Accepted: December 13, 2004 Proofs received from author(s): May 25, 2005 